\title{
Un govern de coalició a la valenciana: el Botànic*
}

\author{
Rosa Roig \\ UNIVERSITAT DE VALÈNCIA
}

rosa.roigfauv.es

ORCID: 0000-0003-2408-8417

Rebut: 07/10/2019

Acceptat: 21/02/2020

\section{RESUM}

Els governs de coalició són una constant en el panorama polític europeu en els diferents àmbits de govern. No obstant això, al llarg de la història de l'autonomia valenciana, aquesta manera de governar és una excepció fins a 2015, quan s'obri una nova etapa amb els anomenats governs del Botànic. Quins factors expliquen aquesta transformació del sistema polític valencià? Quines són les característiques d'aquesta coalició governamental? És un model de govern de coalició exportable? Amb l'objectiu de respondre aquestes preguntes i formular-ne d'altres, primerament s'analitzen les causes que han generat aquesta dinàmica coalicional en el sistema de partits valencià tant l'any 2015 com el 2019. En segon lloc, s'estudia el model de govern de coalició, la seua singularitat. La hipòtesi de treball és que l'èxit en termes d'estabilitat i capacitat governamental del govern de coalició del Botànic s'emmarca en un context polític determinat amb accent valencià.

Paraules clau: coalició governamental, Comunitat Valenciana, política de coalició, Espanya de les autonomies, formació de govern.

\section{ABSTRACT. A Government of Coalition in Valencian terms: el Botànic}

Coalition governments are common in the European political landscape in various tiers of government. However, such coalitions were an exception in the history of the Valencian Autonomy until 2015, which marked a new stage with the so-called El Botànic governments. Which factors explain this change in the Valencian political system? What are the features of such coalition governments? Can this model be applied to other political systems? This paper addresses these and other issues. First, it looks at what led to coalition governments in both 2015 and 2019. Second, it studies the model of coalition government. The hypothesis tested is this: El Botànic is a coalition government whose success in terms of stability and governmental action is framed within a specific Valencian political context.

Keywords: Governmental coalition, Valencian Region, Coalition politics, Spain of the autonomies, Government formation.

*Vull agrair breument l'aportació del professor Antonio Robles Egea amb els seus comentaris. No obstant això, aquest reconeixement no ha de servir per a fer recaure en la seua persona cap responsabilitat sobre aquest treball, que és assumit íntegrament per l'autora.

Aquest estudi es desenvolupa en el marc del projecte d'investigació «Flujos de información y efectos conceptuales, mediadores de la innovación económica y social. Nudgets contra la corrupción» (referència AlCO/2019/053). 
SUMARI

El camí cap a un govern de coalició

El marc jurídic i institucional

El sistema electoral i el sistema de partits

Ideologia i context històric
El mestissatge

Reflexions finals

Annex 1

Referències bibliogràfiques

Autor per a correspondència / Corresponding author: Rosa Roig. Universitat de València, Facultad de Derecho. C/Professor Francisco Tomás I Valiente, 4, 46022 València (España).

Citació suggerida / Suggested citation: Roig, R. (2020). Un govern de coalició a la valenciana: el Botànic. Debats. Revista de cultura, poder $\mathrm{i}$ societat, 134(1), 155-169. DOI: http://doi.org/10.28939/iam.debats.134-1.9

\section{EL CAMÍ CAP A UN GOVERN DE COALICIÓ}

Des de finals del segle xx s'ha debatut en les Corts sobre la necessitat de modificar la llei electoral valenciana —en particular, la barrera electoral del $5 \%$ - per a obrir el poder legislatiu a forces polítiques més menudes més enllà dels populars i els socialistes, protagonistes del bipartidisme durant més de trenta anys. No obstant això, el 2015 el pluralisme penetra en el Parlament sense haver-se reformat el marc electoral, la qual cosa va donar pas al pentapartidisme amb la incorporació de dues noves formacions: Ciudadanos i Podem. Una pluralitat que arriba a l'hexapartidisme el 2019 amb l'entrada d'una altra força política: Vox. Si des de 1983 la fragmentació del sistema de partits estava entorn del 2,5, el 2019 arriba al 5,24 (Taula 2) $i$ es dibuixen nous escenaris que afecten directament el Consell de la Generalitat, la configuració del qual és fruit d'una coalició governamental des de 2015. Quins són els factors explicatius d'aquesta nova dinàmica d'interacció entre les forces polítiques que es materialitza en una coalició governamental? En primer lloc, s'aborda el marc jurídic i institucional. A continuació, s'analitza el sistema electoral i el sistema de partits valencià. Un altre element d'estudi és la ideologia dels membres de la coalició. Finalment, es dirigeix el focus d'atenció als elements històrics, en particular al context històric.

Les teories sobre la formació de governs de coalició solen dividir-se en dos grans grups: les teories formals i les teories multidimensionals. En termes generals, les teories formals es construeixen entorn de les teories d'elecció racional i la teoria de jocs, i els partits polítics es conceben com a simples màquines de poder que persegueixen càrrecs ministerials (Budge i Laver, 1986; Matas, 2015; Reniu, 2010; Strom, 1985 i 1990). Des d'aquesta òptica, els partits emergeixen com a actors racionals que decideixen integrar-se en un executiu de coalició en el supòsit d'una coalició mínima guanyadora — concepte encunyat per Riker (1975) per a definir aquelles coalicions en què la suma dels partits reuneix la majoria absoluta d'escons. Tal com apunta Reniu (2010), aquest enfocament sobre la formació de governs de coalició difícilment pot explicar governs minoritaris com seria el cas del primer Botànic el 2015. Les teories multidimensionals incorporen altres variables com el marc institucional o el sistema de partits, entre d'altres, per comprendre el procés de coalició. Aquest treball s'emmarca dins de les teories multidimensionals. En concret, s'adopta la perspectiva d'anàlisi desenvolupada pel professor Matas (2015) per a l'estudi de la formació d'un govern de coalició i s'identifiquen tres grans grups de variables determinants en el procés: 1) el marc jurídic i institucional, 2) el sistema electoral i el sistema de partits, 3) la ideologia dels partits polítics i el context històric. Des d'aquest enfocament s'analitza el fet coalicional valencià conegut com Botànic per a referir-se als governs de coalició en la Generalitat de la Comunitat Valenciana des de 2015. 


\section{EL MARC JURÍDIC I INSTITUCIONAL}

«El punt de partida de la negociació és, en primer lloc, la voluntat de formar part d'un govern de coalició i, en segon lloc, posseir el suport parlamentari necessari per a impulsar l'acció de govern» (Matas, 2015: 25). Segons el funcionament del sistema parlamentari i els resultats electorals, les formacions polítiques manifestaran la seua voluntat $-\mathrm{O}$ no- de configurar una coalició governamental. A partir d'aquesta òptica, el marc jurídic i institucional emergeix com un factor decisiu en el procés de negociació.

D'acord amb l'Estatut d'autonomia, el candidat a president de la Generalitat per a ser elegit en la primera votació del procés d'investidura ha d'obtenir el suport de la majoria absoluta dels membres de la cambra. Ara bé, en segona votació, amb el suport de la majoria simple pot convertir-se en president $\mathrm{i}$ formar un govern minoritari. No obstant això, un executiu en minoria requereix grans habilitats negociadores - siga per a acordar un pacte de legislatura amb l'oposició o per a aconseguir pactes ad hoc al llarg de la legislatura - per a governar i evitar el bloqueig en seu parlamentària. En altres paraules, la cerca de la majoria absoluta en el legislatiu no respon únicament al procés d'investidura, sinó que també persegueix l'estabilitat política del nou executiu i la seua comoditat en l'exercici de les responsabilitats governamentals, a què s'afegeix el fet que en procediments legislatius especials s'exigeix que els vots a favor en l'hemicicle siguen superiors a la meitat dels escons més un. Per exemple, la reforma de la Llei Electoral Valenciana present en l'agenda pública des de fa uns anys exigeix el suport de dues terceres parts dels membres de les Corts, la qual cosa ha impedit que es reforme, ja que no hi ha hagut cap proposta dels grups que aglutine aquest consens.

Taula 1 Eleccions autonòmiques a la Comunitat Valenciana segons representació parlamentària

\begin{tabular}{|c|c|c|c|c|c|c|c|c|c|c|}
\hline \multirow{2}{*}{$\begin{array}{l}\text { Candidatura } \\
\text { electoral }\end{array}$} & \multicolumn{10}{|c|}{ Eleccions autonòmiques } \\
\hline & 1983 & 1987 & 1991 & 1995 & 1999 & 2003 & 2007 & 2011 & 2015 & 2019 \\
\hline CDS & - & 11,36 & - & - & - & - & - & - & - & - \\
\hline Cs & - & - & - & - & - & - & - & - & 12,66 & 17,45 \\
\hline CC & - & - & - & - & - & - & - & 7,07 & 18,71 & 16,44 \\
\hline EU & $7,51^{* *}$ & $8,03^{* * * *}$ & 7,6 & 11,7 & 6,15 & 6,45 & 8,13 & 5,8 & -- & - \\
\hline PP & $32,11^{*}$ & $23,96^{* * *}$ & 28,1 & 43,3 & 48,63 & 47,9 & 53,22 & 48,6 & 26,98 & 18,85 \\
\hline Podem & - & - & - & - & - & - & - & - & 11,57 & $7,98^{* * * * *}$ \\
\hline PSPV-PSOE & 51,77 & 41,72 & 43,3 & 34,3 & 34,45 & 36,52 & 35,02 & 27,57 & 20,95 & 23,87 \\
\hline UV & - & 9,24 & 10,5 & - & - & - & - & - & - & - \\
\hline Vox & - & - & - & - & - & - & - & - & - & 10,44 \\
\hline
\end{tabular}

\footnotetext{
* En aquesta convocatòria electoral es considera l'aliança d'AP-PDP-UL-UV com a PP.

** En aquesta convocatòria electoral EU fa referència a la candidatura electoral del PCE-PCPV.

*** En aquesta convocatòria electoral l'actual PP concorre a les eleccions com a AP.

**** En aquesta convocatòria electoral EU correspon a l'aliança electoral d'EU-UPV.

***** En aquesta convocatòria electoral Podem correspon a la candidatura electoral d'Unides Podem-EU.
} 
Taula 2 Índex de fragmentació del sistema de partits valencià: NEPP (nombre efectiu de partits polítics)

\begin{tabular}{|l|l|l|l|l|l|l|l|l|l|l|}
$\begin{array}{l}\text { Any inici } \\
\text { legislatura }\end{array}$ & 1983 & 1987 & 1991 & 1995 & 1999 & 2003 & 2007 & 2011 & 2015 \\
\hline NEPP & 2,16 & 3,09 & 2,5 & 2,72 & 2,17 & 2,22 & 2,22 & 2,35 & 4,48 & 5,24 \\
\hline
\end{tabular}

Font: Corts Valencianes, http://www.cortsvalencianes.es. Elaboració pròpia

En aquest marc jurídic, la composició del parlament valencià que donen els resultats electorals de 2015 i 2019 —en els quals cap força política aconsegueix la majoria absoluta (Taula 1) -, els partits es veuen abocats a entendre's i pactar per a poder governar. És possible superar el procés d'investidura amb majoria simple com s'ha indicat anteriorment, però s'insisteix en el fet que l'acció governamental pot ensopegar amb el legislatiu si no es compta amb suficients suports parlamentaris. Només cal esmentar l'aprovació dels pressupostos anuals.

Fórmula NEPP de Laakso i Taagepera (1979): ${ }^{1}$

$$
N=\frac{1}{\sum_{i=1}^{n} p_{i}^{2}}
$$

L'increment del nombre efectiu de partits polítics de 2,16 el 1983 a 5,24 el 2019 resulta en un parlament fragmentat, un escenari que aboca els grups parlamentaris a definir noves pautes de comportament. Entren noves formacions polítiques en les Corts com és el cas de Ciudadanos, Unides Podem o Vox, al mateix temps que es multiplica el pes dels nacionalistes valencians, que concorren ara sota la coalició electoral Compromís, juntament amb els ecolo-

1 El NEPP mesura el nombre efectiu de partits polítics, és a dir, indica el grau de fragmentació del sistema de partits. Aquesta fórmula, l'autoria de la qual correspon a Laakso i Taagepera (1979), es calcula tenint present el suport electoral obtingut per cada formació i la conversió d'aquests vots en escons. Informa sobre la quantitat de formacions polítiques que integra el sistema de partits i el pes que té en relació amb cadascuna. $n$ és el nombre de partits polítics que s'ha pres en consideració, mentre que $P$ fa referència al suport electoral obtingut per la força política (només es comptabilitzen els vots vàlids). gistes (Verds Equo) i els comunistes (IPV). Es generen noves dinàmiques de diàleg i cooperació. S'entreveu que cap partit pot governar sense acords amb la resta de forces polítiques. Es busquen posicions de trobada entre les diferents opcions polítiques que, en aquest cas d'estudi, tenen la màxima expressió en l'entesa entre les forces de l'esquerra amb l'objectiu de governar, la qual cosa comprén tant nomenar un president de la Generalitat com aprovar un programa polític per a ser implementat pel nou Consell. Efectivament, els pactes del Botànic entre Compromís, PSPV-PSOE i Unides Podem-EU són un acord programàtic amb uns eixos generals d'actuació que marquen l'acció de l'executiu i en garanteixen la implementació ja que els tres grups parlamentaris excedeixen la majoria absoluta.

Aquesta majoria absoluta assumeix el paper de punt efectiu de decisió, un concepte propi de les teories formals elaborat per Strom (1985) que resulta molt útil per a entendre la primera etapa del procés, com assenyala Reniu (2010). El punt efectiu de decisió fa referència al mínim suport que requereix una proposta de l'executiu o del legislatiu per a ser aprovada i convertir-se en realitat, un nombre d'escons que varia segons el procediment legislatiu —ordinari o especial-. Es tracta del suport legislatiu que necessita l'executiu per a governar.

En definitiva, el marc jurídic i institucional es presenta com un element determinant i impulsor de qualsevol procés de formació de govern de coalició, siga en termes de designació del president del Consell i els seus membres o en termes d'implementació de polítiques públiques. Aquests objectius immediats presents en qualsevol negociació coalicional no 
són els únics. És apropiat afegir l'anomenada quota de poder polític que correspon a cada soci en la configuració del nou govern en el primer i el segon escalafó, així com el desig d'executar una política que satisfaça els interessos dels ciutadans de manera que s'acabe traduint en un increment del suport electoral com es veurà més endavant.

\section{EL SISTEMA ELECTORAL I EL SISTEMA DE PARTITS}

Un altre element explicatiu de l'inici d'un procés de negociació coalicional és el sistema electoral. Aquest mecanisme transforma les preferències polítiques dels ciutadans en escons en el parlament per mitjà del dret al vot. Això vol dir que el sistema electoral determina la composició de les Corts i, per tant, el sistema de partits valencià.

Una breu aproximació a la normativa electoral valenciana permet conéixer-ne la repercussió en les estratègies de les forces polítiques en el procés coalicional. Assumint com a pròpies les paraules de Martínez Sospedra (1996), es considera que la Llei Electoral Valenciana (LEV) es formula a imatge i semblança de la Llei Orgànica de Règim Electoral General (LOREG), a excepció de l'alta barrera electoral del $5 \%$ enfront del $3 \%$ en l'àmbit espanyol. Totes dues normatives pretenen instal-lar el bipartidisme imperfecte, és a dir, evitar una fragmentació excessiva del sistema de partits i s'afavoreix dues grans formacions polítiques amb possibilitats de governar i es crea una xicoteta oposició incapaç de ser una vertadera alternativa de govern (Martínez Sospedra, 2007; Pallarés, 1991; Sartori, 1994). Aquest model de sistema de partits és fruit de la combinació particular dels tres pilars principals de qualsevol sistema electoral, a saber, la fórmula electoral, la circumscripció i la barrera electoral. La Taula 3, sobre el grau de concentració del vot en populars i socialistes que compara tots dos parlaments —el Congrés dels Diputats i les Corts-, demostra clarament que el bipartidisme imperfecte caracteritza el sistema de partits espanyol i el valencià des dels anys huitanta fins a 2015.

\section{Taula 3 Concentració del vot PP i PSOE en taxes percentuals}

\begin{tabular}{|l|l|l|}
\hline \multicolumn{3}{|c|}{ Concentració vot PP+PSOE } \\
\hline Eleccions & $\begin{array}{c}\text { Congrés dels } \\
\text { Diputats }\end{array}$ & \multicolumn{1}{c|}{ Corts } \\
\hline $1979^{*}$ & 58,8 & - \\
\hline $1983^{* *}$ & 68,64 & 83,88 \\
\hline $1987^{* * *}$ & 57,46 & 65,68 \\
\hline 1991 & 63,68 & 71,4 \\
\hline 1995 & 66,11 & 77,6 \\
\hline 1999 & 68,7 & 83,03 \\
\hline 2003 & 69,12 & 84,42 \\
\hline 2007 & 70,54 & 88,24 \\
\hline 2011 & 65,3 & 76,17 \\
\hline 2015 & 52,07 & 47,83 \\
\hline 2019 & 41,57 & 42,72 \\
\hline
\end{tabular}

* En aquesta convocatòria electoral es considera UCD com l'embrió de l'actual PP.

** En aquesta convocatòria electoral es considera l'aliança d'AP-PDP-UL-UV com PP.

${ }^{* * *}$ En aquesta convocatòria electoral l'actual PP concorre a les eleccions com a AP.

Font: Corts Valencianes, http://www.cortsvalencianes.es. Ministeri de l'Interior, http://www.mir.es. Elaboració pròpia.

El sistema electoral valencià introdueix la fórmula electoral proporcional D'Hondt. No obstant això, aquesta capacitat per a transformar proporcionalment vots en escons que l'identifica ensopega amb la circumscripció electoral i la barrera electoral. Si s'opta per la província com a circumscripció electoral, en la delimitació de la grandària de la circumscripció prevalen els criteris territorials —el principi de representació política - en detriment dels criteris demogràfics —el principi de proporcionalitat política. La Comunitat Valenciana queda dividida en tres grans circumscripcions equivalents a la unitat provincial, independentment del grau de població que reunisquen. Aquesta configuració de la Llei Electoral Valenciana concedeix un valor diferent al vot segons la província on s'emeta (Garrido Mayol et al., 2001; Martín Cubas, 2017). «Igual que la LOREG, la LEV 
Taula 4 Evolució de la volatilitat electoral agregada

\begin{tabular}{|l|l|l|l|l|l|l|l|l|l|l|l|r|}
\hline Eleccions & 1987 & 1991 & 1995 & 1999 & 2003 & 2007 & 2011 & 2015 & 2019 & 2019 \\
\hline Volatilitat & 19,05 & 9,99 & 15,8 & 9,015 & 1,55 & 4,25 & 10,73 & 34,95 & 16,07 & 5,24 \\
\hline
\end{tabular}

Font: Corts Valencianes, http://www.cortsvalencianes.es. Elaboració pròpia.

estableix una sobrerepresentació del vot conservador. Les zones menys poblades, normalment les més conservadores, gaudeixen d'una sobrerepresentació» (Roig, 2019: 493). És el que ocorre a la província de Castelló. En canvi, les zones urbanes i costaneres com València, on el vot d'esquerra és majoritari, pateixen infrarepresentació (Calvet, 2010).

Aquesta desigualtat del valor del vot dels valencians s'aguditza amb la introducció d'una barrera electoral del $5 \%$, la més alta d'Espanya, que suposa dos punts més que el llindar electoral al Congrés dels Diputats, el Parlament de Catalunya o el Parlament Basc. Aquest mecanisme estableix el percentatge de vots que ha d'obtenir una candidatura per a poder participar en la distribució d'escons i formar part del sistema de partits. Tal com ha estudiat Franch i Ferrer $(1995,1996)$, situar-la en el $5 \%$ ha suposat tancar les portes del parlament valencià a formacions polítiques minoritàries com els nacionalistes valencians —els anomenats PANE (partits d'àmbit no estatal)— que sí estan presents en l'àmbit local. D'aquesta manera, es redueix la pluralitat del poder legislatiu al mateix temps que es reforça el pes dels dos partits majoritaris d'àmbit estatal —els PAE— (Calvet, 2014), és a dir, el bipartidisme valencià.

No obstant això, aquest sistema polític pateix un canvi substancial en els comicis de 2015 en el marc de la crisi econòmica i política que afecta Espanya, en general, i la Comunitat Valenciana, en particular, des de 2009 (Méndez Gutiérrez del Valle, 2015). Sorgeixen noves forces polítiques d'àmbit estatal com són Ciudadanos i Podemos, així com una nova coalició electoral valencianista: Compromís, que uneix els nacionalistes valencians (BNV), els comunistes (ICP) i els verds (Verds Equo), amb un missatge rupturista i uns líders joves i carismàtics. Tres opcions electorals que aconsegueixen aglutinar el vot del descontentament cap als partits tradicionals, protagonistes del bipartidisme imperfecte (Roig, 2017).

Després de tres dècades de bipartidisme, la Comunitat Valenciana s'obri al pluripartidisme; pentapartidisme, inicialment, que es transforma en hexapartidisme el 2019. El vot es dispersa fins a tal punt que en la legislatura actual, les Corts estan compostes per sis grups parlamentaris, quan habitualment hi eren dues grans formacions i una força xicoteta (legislatures I, V, VI i VII d'un total de 10 legislatures). Segons l'índex de fragmentació de partits de Laakso i Taagepera, es produeix un increment de més del 40 \% en el nombre de partits en seu parlamentària (vegeu Taula 2). El nombre efectiu de partits passa del 2,35 el 2011 al 4,48 el 2015. El canvi, de 2015 a 2019 és molt menor, ja que només s'afegeix una força política més al pluripartidisme moderat de 2015 i passa de 4,48 a 5,24.

Fórmula Pedersen (1979): ${ }^{2}$

$$
V=\frac{1}{2} \sum_{i=1}^{n}\left|P_{i, t}-P_{i, t-1}\right|
$$

2 L'índex de volatilitat electoral agregada mesura el percentatge net de votants que canvien de vot d'unes eleccions a unes altres. El valor 0 indica que cap partit ha guanyat ni ha perdut vots. En canvi, el valor 100 assenyala que tot l'electorat ha preferit opcions polítiques diferents. Ningú ha votat algun dels partits que van obtenir representació parlamentària en els comicis previs. Aporta informació sobre la magnitud del canvi del sistema de partits polític. Per a entendre la fórmula cal saber que $n$ fa referència al nombre de partits que es tenen en compte d'una cita electoral a l'altra. $P$ es refereix al suport electoral percentual que rep el partit $i$ en unes eleccions, mentre que $P_{+}+1$ és el suport electoral en percentatge que obté el partit $i$ en els comicis següents. És important tenir en compte que les diferències es consideren en valor absolut. 
La magnitud del canvi del sistema de partits s'aprecia a través de l'anàlisi de l'índex de volatilitat electoral. La modificació de l'orientació del vot de bona part de l'electorat es tradueix en un transvasament de vots dels dos grans partits tradicionals -PP i PSPV-PSOE- a noves formacions polítiques —Ciudadanos, Podem i la nova coalició electoral Compromís-. Aquest indicador mostra el grau de descontentament o satisfacció de la ciutadania amb la candidatura electoral que va votar en els comicis anteriors. El canvi del vot reflecteix el càstig que reben populars i socialistes, especialment el PP, que ha ostentat la presidència del Consell durant més de trenta anys.

Des d'una perspectiva històrica, l'evolució d'aquest índex marca la transformació del sistema de partits valencià. Del bipartidisme inicial liderat pels socialistes i el bipartidisme de la segona etapa dirigit pels populars el 2015 s'arriba a un pluripartidisme moderat, que es consolida el 2019. La major volatilitat es produeix en les eleccions de 2015 , en què emergeix un nou mapa polític amb un índex entorn del $35 \%$. Aquest canvi del vot sintetitza la desconfiança de la ciutadania cap als partits tradicionals i l'aposta per opcions polítiques diferents a través d'un procés de dispersió del vot que trenca amb la dinàmica centrípeta que caracteritza el bipartidisme valencià i reprodueix la dinàmica del sistema de partits espanyol.

És cert que aquestes transferències de vots en el sistema electoral dibuixen un nou mapa polític, però PP i PSPV-PSOE continuen mantenint-se al capdavant com a principals forces en el nou context del pluralisme de partits. Són encara les dues formacions majoritàries dins del sistema de partits, així com dins dels respectius blocs ideològics, la dreta i l'esquerra. La dimensió del grup parlamentari és important per a poder assumir un paper de més o menys pes en el procés de negociacions per a formar un govern de coalició.

\section{IDEOLOGIA I CONTEXT HISTÒRIC}

La variable ideològica també incideix en el procés de formació d'un govern de coalició. Pot ser un element d'acostament o bé un factor d'allunyament entre els partits polítics. Evidentment, la repercussió que tinga depén de la necessitat d'arribar a acords per a governar. En altres paraules, si s'obté la majoria absoluta, és probable que el partit guanyador intente governar en solitari sense suports. Per contra, en un marc electoral com el de 2015 o el de 2019 a la Comunitat Valenciana, on cap força política pot garantir un govern en solitari i estable, l'escenari és diferent.

La dispersió del vot que s'aprecia per mitjà de l'índex de volatilitat agregada (vegeu Taula 4) comporta que els partits polítics en el parlament valencià intenten pactar per configurar l'executiu. Lògicament, es busquen punts d'acord amb aquelles formacions de més afinitat ideològica, distingint entre el bloc d'esquerres i el bloc de dretes. Segons la composició de les Corts, l'esquerra aglutina Compromís, Podem i PSPV-PSOE, mentre que la dreta comprén Ciudadanos, PP i Vox.

Des d'aquest enfocament, les possibilitats d'iniciar la negociació per a una coalició governamental poden ser diverses, com s'observa en la Taula 5 sobre resultats electorals. Tant Ciudadanos com PSPV-PSOE apareixen en dues possibles coalicions diferents, fruit de la seua relativa centralitat respecte de la resta de forces polítiques. Aquell actor que se situe en el centre tindrà més probabilitats d'arribar a acords, ja siga per la dreta o per l'esquerra. També incideix el nombre d'escons obtinguts i l'experiència en la capacitat de negociació de cada força política en la dinàmica coalicional (Robles Egea, 2004).

Amb un parlament de 99 escons, la majoria absoluta a les Corts se situa en $49+1$, és a dir, 50 diputats. En aquest marc institucional, si les parts negociadores aspiren a un govern estable i amb capacitat per a implementar el programa polític que gaudisca de la confiança del poder legislatiu, lògicament, la primera opció és una coalició governamental per 
Taula 5 Possibles governs de coalició segons ideologia

\begin{tabular}{|c|c|c|c|c|c|c|}
\hline \multirow[b]{2}{*}{ Eleccions } & \multicolumn{2}{|l|}{ Esquerra } & \multicolumn{2}{|c|}{ Centre } & \multicolumn{2}{|c|}{ Dreta } \\
\hline & Integrants & Escons & Integrants & Escons & Integrants & Escons \\
\hline 2015 & PSPV-PSOE+Comp+Podem & 55 & PSPV-PSOE + CS & 36 & $\mathrm{PP}+\mathrm{Cs}$ & 44 \\
\hline 2019 & PSPV-PSOE+Comp+Podem & 52 & PSPV-PSOE+CS & 45 & $P P+C s+V_{0 x}$ & 47 \\
\hline
\end{tabular}

Font: Corts Valencianes, http://www.cortsvalencianes.es. Elaboració pròpia.

l'esquerra. S'hi aconsegueix la majoria absoluta al mateix temps que es produeix un acostament ideològic. La resta de possibilitats no sumen els 50 diputats que blinden l'executiu enfront d'una moció de censura i aporten estabilitat a l'executiu en l'exercici de les seues responsabilitats.

Com s'ha esmentat inicialment, un procés de govern coalicional no se circumscriu a la configuració de l'executiu, sinó que també es té en consideració el fet de poder exercir l'acció governamental. Des d'aquest enfocament, és condició sine qua non que les parts negociadores coincidisquen en un mínim programa polític, la qual cosa significa que les parts han de buscar punts de consens per a elaborar una proposta d'acció de govern que després es puga implementar. En paraules de Robles Egea (2000: 47): «els actors tracten d'aconseguir el resultat ideològicament més homogeni de cara a dur a terme els programes polítics futurs».

No cal oblidar que un objectiu fonamental de qualsevol partit polític és incrementar el suport electoral que té en els comicis següents, ampliar-ne els votants. Substantivament això implica que la seua posició en la negociació està condicionada pel seu programa polític de cara als seus electors. Un punt de partida que l'acosta a aquells actors amb qui siga menys difícil aconseguir un mínim comú denominador en termes d'acció governamental.

El context en què es desenvolupen les negociacions influeix en el paper de la variable de la ideologia. Les eleccions autonòmiques i municipals de 2015 inau- guren un nou cicle polític a Espanya (Llera, 2015; Orriols i Cordero, 2016). La diutadania castiga els dos grans partits espanyols, que s'han encarregat de gestionar la crisi des que va començar. Si els socialistes van ser expulsats del govern l'any 2011, el 2015 els populars són els grans perdedors. Els votants rebutgen la resposta del PP a la crisi amb una política de retallades de l'estat del benestar combinada amb una pujada d'impostos, mentre es rescaten les entitats financeres. Un partit que es veu esguitat per diferents casos de corrupció, entre els quals destaca la trama Gürtel, en què està particularment immers el PP valencià, que en aquells moments ostentava la presidència del Govern de la Generalitat.

D'aquesta manera, els comicis autonòmics valencians de 2015 transcorren en un clima de desig de canvi, la qual cosa explica el transvasament de vots dels populars, fonamentalment, i dels socialistes cap a altres formacions amb un discurs electoral protagonitzat per la paraula canvi a través de nous líders polítics que projecten una ruptura amb el bipartidisme (López García et al., 2016). En aquesta conjuntura, cal analitzar les estratègies postelectorals dels partits polítics amb representació parlamentària en les Corts per a configurar el Consell, a excepció dels populars. Tots ells onegen la bandera del canvi i la diferència respecte del partit en l'executiu immers en diferents causes judicials per corrupció i responsable de la resposta política valenciana a la crisi. En conseqüència, ni Ciudadanos, ni Compromís, ni Podem, ni PSPV-PSOE es mostren favorables a pactar amb el PP per a formar el Consell. Els populars han estat en el govern durant més de tres dècades i 
l'escenificació del canvi implica apartar aquest partit del govern.

L'element del canvi assumeix el paper de motor impulsor de les negociacions. S'albira la possibilitat d'obrir una nova etapa en la política valenciana sense els populars en la Generalitat després de més de tres dècades en l'executiu. Com a resultat, el partit que es quede al marge de la coalició apareixerà davant de l'electorat com aquell que no ha promogut l'inici d'una nova etapa en la política valenciana. Els socialistes inicien el procés de negociacions $i$, si bé és cert que en un primer moment juguen a l'ambigüitat que els permet el fet de ser un partit de centreesquerra i miren tant els socis de la dreta —Ciudadanos- com els de l'esquerra —Compromís i Podem-, prompte s'adonen que han de quedar-se en el bloc d'esquerres, que aporta la majoria absoluta requerida per a l'estabilitat governamental i una aproximació ideològica en matèria de polítiques socials, educació i sanitat. Aquest primer pas donat pel PSPV-PSOE el converteix en un jugador dominant en la dinàmica coalicional i li atorga la recompensa més gran: la presidència del Consell.

Compromís, malgrat el rebuig inicial, també constata que és una oportunitat històrica per a formar part del Consell. Mai abans havia tingut la possibilitat de governar des de la Generalitat. Podem, en canvi, tria una posició un poc ambigua, que rectifica després dels comicis de 2019. Inicialment, aposta per un nou govern d'esquerres valencià, però sense assumir competències executives. El seu suport al canvi és des del legislatiu i per mitjà de la signatura de l'Acord del Botànic. No entra en el Consell. El Botànic de 2015 i les reformes posteriors, així com l'edició de 2019, recullen els objectius programàtics sobre els quals s'articulen les polítiques públiques.

El consens sobre les línies generals que han de guiar l'acció governamental del nou executiu serveix d'estímul per al pacte sobre les quotes de poder de les parts en el nou executiu. Cal recordar que, durant la campanya electoral, Compromís i Podem es presenten com el canvi enfront dels socialistes i es distan- cien del PSPV-PSOE en el discurs. No obstant això, aquest acord ideològic contribueix a engendrar un clima de confiança i il-lusió pel canvi d'etapa política entre les parts i el seu electorat, encara que per a les dues noves formacions d'esquerra implique pactar amb un dels dos partits clàssics. Amb l'objectiu de generar confiança, es decideix introduir un mètode relativament nou en matèria de repartiment de parcel-les de poder dels socis en el govern de coalició: el mestissatge.

\section{EL MESTISSATGE}

L'interés pel govern de coalició del Botànic no resideix únicament en el procés de negociació, sinó també en el funcionament. Una de les singularitats és la distribució de les quotes de poder en el Consell entre les formacions integrants. Com tota coalició governamental, les parts persegueixen la maximització de les parcel-les de poder, però per aconseguir aquest objectiu s'introdueix una metodologia relativament nova: el mestissatge. Un mètode que s'aplica per primera vegada en el govern de coalició entre socialistes i nacionalistes en la Xunta de Galicia en 2005, però que no té massa èxit, ja que en les eleccions següents els populars recuperen la majoria absoluta i es mantenen en el poder avui dia. Entre els problemes que se li atribueixen destaca la falta de coordinació entre els socis, les postures divergents dels quals es mostren en públic, la qual cosa reflecteix la falta de coordinació en el si de l'executiu. Fins a 2015 no torna a aplicar-se en una coalició governamental en l'arena autonòmica.

Sota el concepte de mestissatge s'aplica una fórmula particular de repartiment de càrrecs polítics entre els socis que afecta el segon grau de l'executiu, és a dir, subsecretaries, secretaries autonòmiques i direccions generals. Aquest sistema implica que, per davall de cada conseller, l'altre partit ha d'assignar un secretari autonòmic i un terç de les direccions generals. Un mètode que vol evitar crear departaments estancs per a un únic partit i enfrontaments entre les parts, al mateix temps que es genera cohesió interna en 
l'executiu. Funciona com un sistema de pesos i contrapesos en el si del Consell.

No obstant això, a l'inici del primer Botànic, prompte es constata que aquesta via pot ser un obstacle per a les accions de govern arran dels enfrontaments personals en certes àrees com són Presidència i la Conselleria d'Economia. A causa d'això, s'opta per excloure d'aquest sistema de repartiment de poder la Presidència i la Vicepresidència, en què el personal correspon íntegrament al titular. Així, els socialistes designen tot el personal de Presidència, mentre que Compromís s'encarrega del personal de Vicepresidència i de la Conselleria d'Igualtat i Polítiques Inclusives, unides en la figura de Mónica Oltra, excepte en el cas de la Direcció General de Dones, que recau en mans del PSPV-PSOE. Aquest bloqueig de Presidència i Vicepresidència s'ha mantingut en la segona edició de 2019 amb l'entrada d'Unides Podem-EU, la qual cosa implica que tots els càrrecs de la Vicepresidència Segona i la Conselleria d'Habitatge i Arquitectura Bioclimàtica són nomenats pel titular, Martínez Dalmau.

Aquest model de distribució del poder en el Consell s'ha qualificat com un element diferenciador en els governs de coalició a Espanya. Implica que el conseller ha de tenir entre els seus col-laboradors més pròxims l'altre soci o socis, que assumeixen el paper de fiscalitzadors des de dins del mateix executiu. S'obliga al diàleg, a la negociació i a la transparència en l'acció de govern de manera contínua entre els socis i fora de l'executiu de cara a la ciutadania. La coordinació entre les parts és imprescindible per a la construcció del discurs del govern a través del portaveu. El mestissatge emergeix com un protocol intern en la coalició per a assegurar l'èxit i fixa unes normes de comportament que exigeixen més habilitat política. Al mateix temps, aquesta tècnica desenvolupa una pràctica política molt més democràtica des del punt de vista de l'impuls de les institucions.

El fet que el 2015 un dels socis signants de l'Acord del Botànic - Podem- decidisca no entrar en el govern i trie exercir suport parlamentari com un actor extern facilita tant l'acció governamental com la distribució de les parcel-les de poder en el Consell. Les negociacions per a formar el govern de coalició es desenvolupen únicament entre dues parts, mentre que el 2019 en són tres. L'opció d'Unides Podem-EU d'integrar-se en l'executiu l'any 2019 incorpora un nou interlocutor per a la negociació interna de l'acció de govern, a la qual s'afegeix la suma un nou actor que també desitja participar en el repartiment de càrrecs polítics. Aquesta nova posició del tercer soci en l'acord programàtic del segon Botànic juntament amb el mapa electoral dibuixat després dels comicis, en què els socialistes incrementen els seus votants mentre que Compromís i Unides Podem-EU perden pes electoral, comporta una nova interpretació de la metodologia del mestissatge. En primer lloc, ja no s'exclouen únicament la Presidència i les vicepresidències primera i segona d'aquest mecanisme, sinó que també en queda exempta la Conselleria de Participació, Transparència, Cooperació i Qualitat Democràtica, en mans d'Unides Podem-EU. En segon lloc, no s'incorporen col-laboradors d'Unides Podem-EU a les conselleries que no ostenten els seus líders. No és un mestissatge a tres com correspondria, ja que són tres socis de govern. És un mestissatge relatiu. Solament s'aplica a set conselleries de les onze que hi ha -tenint en compte que dues d'elles gaudeixen de rang de vicepresidència. I únicament concerneix a col-laboradors de Compromís i PSPV-PSOE, ja que Unides Podem-EU no participa en l'aplicació d'aquest mecanisme.

L'estudi de la composició del Consell permet apreciar la importància del bon clima de cooperació entre les parts per a configurar un executiu de coalició. La generositat es converteix en companya inseparable de la confiança per poder tenir èxit en la configuració del govern. El 2015 els dos socis del govern acorden redistribuir el seu pes en l'executiu en dues parts iguals en matèria de nombre de conselleries, de les quals la Presidència correspon al partit polític més votat i la Vicepresidència-Portaveu, juntament amb la Conselleria d'Igualtat i Polítiques Inclusives, a l'altra formació. L'executiu està integrat per nou 
Taula 6 Distribució quotes de poder en el Consell

\begin{tabular}{|c|c|c|c|c|c|c|c|c|c|c|c|c|}
\hline \multirow[b]{3}{*}{$\begin{array}{l}\text { Elec- } \\
\text { cions }\end{array}$} & \multicolumn{4}{|c|}{ Compromís } & \multicolumn{4}{|c|}{ Unides Podem-EU } & \multicolumn{4}{|c|}{ PSPV-PSOE } \\
\hline & \multicolumn{2}{|c|}{$\begin{array}{c}\text { Aportació } \\
\text { escons }\end{array}$} & \multicolumn{2}{|c|}{$\begin{array}{c}\text { Participació } \\
\text { Consell }\end{array}$} & \multicolumn{2}{|c|}{$\begin{array}{c}\text { Aportació } \\
\text { escons }\end{array}$} & \multicolumn{2}{|c|}{$\begin{array}{c}\text { Participació } \\
\text { Consell }\end{array}$} & \multicolumn{2}{|c|}{$\begin{array}{l}\text { Aportació } \\
\text { escons. }\end{array}$} & \multicolumn{2}{|c|}{$\begin{array}{c}\text { Participació } \\
\text { Consell }\end{array}$} \\
\hline & Escons & $\begin{array}{c}\text { Pes escons } \\
\text { Consell }\end{array}$ & $\begin{array}{c}\text { Membres } \\
\text { executiu }\end{array}$ & $\begin{array}{c}\text { Pes } \\
\text { executiu }\end{array}$ & Escons & $\begin{array}{c}\text { Pes escons } \\
\text { Consell }\end{array}$ & $\begin{array}{c}\text { Membres } \\
\text { executiu }\end{array}$ & $\begin{array}{c}\text { Pes } \\
\text { executiu }\end{array}$ & Escons & $\begin{array}{c}\text { Pes escons } \\
\text { Consell }\end{array}$ & $\begin{array}{c}\text { Membres } \\
\text { executiu }\end{array}$ & $\begin{array}{c}\text { Pes } \\
\text { executiu }\end{array}$ \\
\hline 2015 & 19 & $34,54 \%$ & 5 & $50 \%$ & 13 & $23,63 \%$ & 0 & $0 \%$ & 23 & $41,81 \%$ & 5 & $50 \%$ \\
\hline 2019 & 17 & $32,69 \%$ & 4 & $33,33 \%$ & 8 & $15,38 \%$ & 2 & $16,67 \%$ & 27 & $51,92 \%$ & 6 & $50 \%$ \\
\hline
\end{tabular}

Font: Corts Valencianes, http://www.cortsvalencianes.es, i Generalitat, http://www.gva.es. Elaboració pròpia

conselleries i la Presidència. Cinc membres corresponen a Compromís i els altres cinc, al PSPV-PSOE. Aquest repartiment a parts iguals no té en compte el suport electoral obtingut per cada força. I en el segon escalafó del Consell s'aplica el mestissatge com s'ha explicat anteriorment. L'any 2019, en canvi, la presència de cada formació en l'executiu és equivalent al pes percentual en el nombre de diputats que s'aporta (vegeu Taula 6).

La lectura de les dades recollides en la Taula 6 indica que, per a poder arribar a formar el Botànic, les tres parts han hagut de ser generoses amb els seus socis a fi de poder aconseguir un govern de coalició. Si l'any 2015 els socialistes decideixen situar-se d'igual a igual amb els nacionalistes valencians en la composició del Consell malgrat aportar més escons a la coalició, el 2019 PSPV-PSOE i Compromís han de mantenir la mateixa disposició negociadora perquè el tercer soci entre en l'executiu. Les negociacions ja no són bilaterals, sinó trilaterals. El poder ha de redistribuir-se entre tres parts, la qual cosa multiplica les dificultats. Les reticències dels nacionalistes valencians a perdre la seua posició política en el si de l'executiu i les demandes de Podem per a ser un soci equivalent a Compromís són un obstacle perquè el segon Botànic veja la llum. La conciliació d'interessos diversos entre les parts es presenta complicada. Efectivament, fins al mateix dia del debat d'investidura els tres socis no adopten un acord sobre les conselleries i les vicepresidències en una reunió breu entre els tres líders. Després queda pendent l'estructura orgànica de la Generalitat: la negociació tampoc és fàcil i acaba amb un increment del personal que trenca amb el missatge d'austeritat del primer Botànic, però aconsegueix satisfer els interessos dels tres socis.

D'una banda, respecte de 2015, es passa de nou a onze conselleries, la qual cosa repercuteix en l'estructura orgànica de la Generalitat. De les deu subsecretaries de la legislatura passada, s'arriba a dotze. Les 22 secretaries autonòmiques es converteixen en 29. Les 56 direccions generals es transformen en 85. No obstant això, l'increment de personal més gran es produeix en el cas dels assessors, que en sumen 116, quan en la legislatura anterior n'hi havia entorn de 70, sense arribar al límit de 74 persones establert pel mateix Consell en el Decret 185/2015, de 16 d'octubre, del Consell pel qual es regula el personal i els llocs de naturalesa eventual de l'Administració de la Generalitat. D'altra banda, en termes percentuals, nacionalistes i socialistes realitzen concessions. Els socialistes -que sumen quatre diputats més- participen amb la mateixa quota de poder en termes percentuals que el 2015, mentre que els nacionalistes - que perden tres diputatshan de cedir una conselleria a Unides Podem-EU -qui arriba a perdre cinc diputats respecte de la legislatura anterior. Aquesta ampliació de càrrecs polítics resulta en l'augment d'un conseller per als socialistes, el mateix pes polític per als nacionalistes en termes absoluts, gràcies a l'increment de secretaries autonòmiques i direccions generals, i 
dues conselleries per a Unides Podem-EU, una de les quals gaudeix d'un rang de Vicepresidència Segona. En resum, la materialització d'un govern de coalició sols és possible si el mercadeig de càrrecs polítics en les negociacions satisfà totes les parts, tant en el primer escalafó —el Govern-com en el segon -l'estructura orgànica de l'executiu.

Aquesta configuració de l'executiu és possible principalment per tres raons que acompanyen a aquesta actitud de voluntat d'acord per les parts. En primer lloc, cal destacar que els socialistes no governaven la Generalitat des de 1995 i han perdut totes les conteses electorals des d'aleshores. Accedir ara a la Presidència de la Generalitat els permetrà recuperar la visibilitat política i presentar-se com una força de govern. En segon lloc, Compromís mai ha tingut l'oportunitat d'accedir al Consell per l'insuficient suport electoral obtingut a escala autonòmica. És també una oportunitat històrica per a projectar una imatge de partit autonòmic que va més enllà de l'àmbit municipal, on ha desenvolupat la seua història. Finalment, cal destacar que el pacte entre les formacions no se cenyeix únicament a l'arena autonòmica, sinó que també comporta acords per a governar junts en l'esfera municipal i presentar-se com a alternativa a la dreta. Els nacionalistes valencians i els socialistes pacten que en aquells ajuntaments on tinguen possibilitat de governar es donaran suport mútuament i assignaran l'alcaldia a la formació més votada. Allà on els resultats electorals ho permeten, s'intenta expandir el model del Botànic a l'àmbit local, tot i que sempre n'hi ha excepcions. Com a conseqüència, si la Presidència de la Generalitat l'ostenten els socialistes amb Ximo Puig, l'Alcaldia de la capital valenciana recau en els nacionalistes valencians amb Joan Ribó. L'Ajuntament de València ofereix una gran visibilitat que satisfà Compromís dins de la lògica del bargaining inherent a qualsevol negociació (Barón, 1991; Laver i Schofeld, 1991).

\section{REFLEXIONS FINALS}

El model de govern de coalició valencià del Botànic és una realitat perquè els resultats electorals impulsen els partits a pactar, fruit de la fragmentació política. No només l'aritmètica fixa la dinàmica coalicional, sinó que la cerca d'estabilitat i el desig d'implementar un programa polític concret exigeix també sumar la majoria absoluta en el parlament. En segon lloc, la proximitat ideològica entre les parts els permet consensuar un projecte polític marc de l'acció governamental. En tercer lloc, són conscients que els rèdits polítics de l'executiu han de compartir-se entre els socis. Per aquest motiu es creen tres llocs amb visibilitat per als líders de les tres formacions: la Presidència i les dues vicepresidències. Tots han d'obtenir-ne beneficis - payoff-: incorporar propostes d'acció governamental i ostentar càrrecs polítics en el Consell en el primer i en el segon escalafó, més enllà dels assessors. En quart lloc, s'aprecia un talent conciliador que afavoreix la negociació i revisió constant del pacte per les parts tant pel que fa a l'acció de govern com a la distribució dels càrrecs polítics en l'organigrama del Consell. Un govern de coalició autonòmic que naix en un context de canvi, el fastig de la ciutadania de la crisi econòmica que esclata el 2009 i els casos de corrupció que impliquen el partit polític en el govern valencià des de feia tres dècades. 


\section{ANNEX 1}

\section{Taula 7 Sigles de les formacions polítiques}

\begin{tabular}{|c|c|}
\hline SIGLES & NOM \\
\hline AP & Aliança Popular \\
\hline $\mathrm{CC}$ & Coalició Compromís Pel País Valencià \\
\hline BNV & Bloc Nacionalista Valencià \\
\hline CDS & Centre Democràtic i Social \\
\hline Cs & Ciudadanos \\
\hline IPV & Iniciativa de Poble Valencià \\
\hline EU & Esquerra Unida \\
\hline PCE & Partit Comunista d'Espanya \\
\hline PDP & Partit Demòcrata Popular \\
\hline PODEM & Podem \\
\hline PP & Partit Popular \\
\hline PSPV-PSOE & Partit Socialista del País Valencià-Partit Socialista Obrer Espanyol \\
\hline UL & Unión Liberal \\
\hline Unides Podem-EU & Unides Podem-Esquerra Unida \\
\hline UPV & Unitat del Poble Valencià \\
\hline UV & Unió Valenciana \\
\hline Verds Equo & Verds Equo \\
\hline
\end{tabular}

Font: Corts Valencianes, http://www.cortsvalencianes.es. Elaboració pròpia.

\section{REFERÈNCIES BIBLIOGRÀFIQUES}

Barón, D. P. (1991). A Spatial Bargaining Theory of Government Formation in a Parliamentary System. American Political Science Review, 85, 137-164. doi: 10.2307/1962882

Budge, I. i Laver, M. (1986). Office Seeking and Policy Pursuit in Coalition Theory. Legislative Studies Quarterly, 11(4), 485-506.

Calvet Crespo, J. (2014). Los gobiernos de coalición en la Comunidad Valenciana. En J. M. Reniu (ed.), Los gobiernos de coalición en las comunidades autónomas españolas (p. 361-379). Barcelona: Atelier.

Calvet Crespo, J. (2010). El sistema electoral de les Corts Valencianes: Orígens i reforma. Corts. Anuari de Derecho Parlamentario, 23, 225-256.

Franch i Ferrer, V. (1996). Las elecciones del cambio: Las autonómicas y municipales del 28 de mayo de 1995. Revista Valenciana d'Estudis Autonòmics, 15, 101-262.

Franch i Ferrer, V. (1995). Las elecciones autonómicas valencianas en perspectiva (1983-1991): Los efectos de la cláusula de la barrera del 5\% en el sistema de partidos valenciano. Cuadernos Constitucionales de la Cátedra Fadrique Furió Ceriol, 9/10, 87-113. 
Garrido Mayol, V., Martín Cubas, J. i Sóler Sánchez, M. (2001). El nacimiento del Estatuto Valenciano. València: Fundación Profesor Manuel Broseta.

Laakso, M. i Taagepera, R. (1979). "Efective" Number of Parties: A Measure with Application to West Europe. Comparative Political Studies, 12(1), 3-27.

Laver, M. i Schofeld, N. (1991). Multiparty Government: The Politics of Coalition in Europe. Nova York: Oxford University Press.

Llera, F. (2015). Victoria popular y realineamiento en las elecciones locales, autonómicas, insulares y forales 2015. Sistema, 240, 3-34.

López García, G., Cano Orón, L. i Argilés Martínez, L. (2016). Circulación de los mensajes y establecimiento de la agenda en Twitter: El caso de las elecciones autonómicas de 2015 en la Comunidad Valenciana. Trípodos, 39, 163-183.

Matas, J. (2015). La formación de un gobierno de coalición. València: Tirant Lo Blanch.

Martín Cubas, J. (2016). El Estatuto de Autonomía como marco normativo de una reforma del sistema electoral de les Corts Valencianes. Drets. Revista Valenciana de Reformes Democràtiques, 1, 99-129.

Martínez Sospedra, M. (2007). Sobre la necesidad de una ley electoral valenciana. Corts. Anuari de Derecho Parlamentario, 18, 121-145.

Martínez Sospedra, M. (1996). Participación Política, Autonomía y Ley Electoral. La Ley Electoral Valenciana. Corts: Anuario de Derecho Parlamentario, 2, 15-50.

Méndez Gutiérrez del Valle, R. (2015). Atlas de la crisis. València: Tirant Lo Blanch.

Orriols, L. i Cordero, G. (2016). The Breakdown of the Spanish Two-party System: The Upsurge of Podemos and Ciudadanos in the 2015 General Election. South European Society and Politics, 21(4), 469-492. doi: 10.1080/13608746.2016.1198454

Pallarés, F. (1991). Estado autonómico y sistema de partidos: Una aproximación electoral. Revista de Estudios Políticos, 71, 281-323.

Pedersen, M. N. (1979). The Dynamics of European Party Systems: Changing Patterns of Electoral Volatility. European Journal of Political Research, 7, 1-26.

Reniu, J. M. (2010). Els governs de coalició. Barcelona: Universitat Oberta de Catalunya.

Riker, W. H. (1975). The Theory of Political Coalitions. New Haven: Yale University Press.

Robles Egea, A. (2004). Negociaciones, payoffs y estabilidad de los gobiernos de coalición. Revista de Estudios Políticos, $126,91-112$.

Robles Egea, A. (2000). El estudio de las coaliciones políticas. En J. Matas (ed.), Coaliciones políticas y gobernabilidad (p. 21-57). Barcelona: Institut de Ciències Polítiques i Socials.

Roig, R. (2019). Del bipartidismo al pentapartidismo: Nueva dinámica ideológica. En Una vida dedicada al Parlamento: Estudios en Homenaje a Lluís Aguiló i Lúcia (p. 491-508). València: Corts Valencianes.

Roig, R. (2017). Dinámica ideológica en el ámbito local. Gobiernos de coalición. Estudio de caso: Alicante, Castellón y Valencia. Corts: Anuario de Derecho Parlamentario, 29, 397-426.

Sartori, G. (1994). Ingeniería constitucional comparada: una investigación de estructuras, incentivos y resultados. Ciutat de Mèxic: Fondo de Cultura Económica.

Strom, K. (1990). A Behavioral Theory of Competitive Political Parties. American Journal of Political Science, 34(2), 565-598.

Strom, K. (1985). Governi di minoranza e democrazie parlamentari. Rivista Italiana de Scienza Politica, 15, $167-204$. 


\section{NOTA BIOGRÀFICA}

Rosa Roig és doctora en Ciències Polítiques, professora associada de la Universitat de València i membre de l'IUED de la UV així com de l'ECPR Steering Committee on Gender and Politics. Investigadora visitant a la University of Kent, l'Instituto Universitário de Lisboa i la Johannes Gutenberg-Universität Mainz. Integrant de diferents projectes de R+D+i: EUROPUB, GIPEyOP, Análisis jurídico y sociológico de las brechas de género en las transiciones trabajojubilación-trabajo, entre d'altres. 